\title{
Impacts of Extreme Weather and Climate on Terrestrial Biota*
}

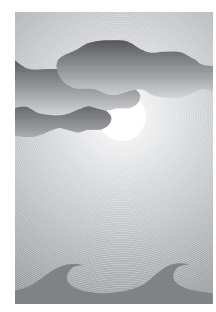

\author{
Camille Parmesan, ${ }^{+, \&}$ Terry L. Root, ${ }^{\#}$ and Michael R. Willig ${ }^{@}$
}

\begin{abstract}
Climate is a driver of biotic systems. It affects individual fitness, population dynamics, distribution and abundance of species, and ecosystem structure and function. Regional variation in climatic regimes creates selective pressures for the evolution of locally adapted physiologies, morphological adaptations (e.g., color patterns, surface textures, body shapes and sizes), and behavioral adaptations (e.g., foraging strategies and breeding systems). In the absence of humans, broad-scale, long-term consequences of climatic warming on wild organisms are generally predictable. Evidence from Pleistocene glaciations indicates that most species responded ecologically by shifting their ranges poleward and upward in elevation, rather than evolutionary through local adaptation (e.g., morphological changes). But these broad patterns tell us little about the relative importance of gradual climatic trends as compared to extreme weather events in shaping these processes. Here, evidence is brought forward that extreme weather events can be implicated as mechanistic drivers of broad ecological responses to climatic trends. They are, therefore, essential to include in predictive biological models, such as doubled $\mathrm{CO}_{2}$ scenarios.
\end{abstract}

\section{Introduction}

The two most commonly measured forms of biological response to climate change are changes in species' geographical distributions and in timing of activity. We begin with a discussion of distributional shifts, since at present these are better understood in relation to extreme weather events. For many species, habitat exists beyond their distributional limits that would be suitable but for climatic factors. In such

\footnotetext{
*This is the fifth of five papers in the "Understanding Changes in Weather and Climate Extremes" series.

+National Center for Ecological Analysis and Synthesis, University of California, Santa Barbara, Santa Barbara, California.

\#School of Natural Resources and Environment, University of Michigan, Ann Arbor, Michigan.

${ }^{\circledR}$ Program in Ecology and Conservation Biology, Department of Biological Sciences and the Museum, Texas Tech University, Lubbock, Texas.

${ }^{\&}$ Current affiliation: Department of Integrative Biology, University of Texas at Austin, Austin, Texas.

Corresponding author address: Dr. Camille Parmesan, Integrative Biology, University of Texas at Austin, Austin, TX 78712.

E-mail: parmesan@mail.utexas.edu

In final form 6 October 1999.

(C)2000 American Meteorological Society
}

cases, ranges are limited by climate (Coope 1995; Grace 1987; Woodward 1987; Graham 1986; Root 1988a; Andrewartha and Birch 1954). As the distance to the edge of the range for a species decreases, individuals often experience increasingly stressful climatological conditions resulting in fewer, smaller patches of suitable habitat, or in decreased reproduction (Brown et al. 1996; Hoffman and Parsons 1997; Carter and Prince 1988; MacArthur 1972). Thus, individuals living along range boundaries are often living at the edge of their species' physiological tolerances and thus are more likely than those living in the interior to experience stressful, harmful, or lethal weather events (Hoffman and Parsons 1997).

Therefore, even if the statistical distribution of extreme events remains the same (i.e., if the tails of the distributions retain a fixed shape even as mean temperature and precipitation shift), the absolute number of days that lie outside of the physiological tolerance of a particular species may increase. Further, this increase in extremes is most likely to affect population and individuals at the edge of the species range.

Mounting evidence indicates that species are currently responding to twentieth century warming by shifting their ranges poleward and upward in altitude (Parmesan et al. 1999; Pounds et al. 1999; Sagarin 
et al. 1999; Thomas and Lennon 1999; Parmesan 1996; Barry et al. 1995; Grabbherr et al. 1994; Hersteinsson and MacDonald 1992). Knowledge of precise causal factors is usually unavailable, either because the basic biology is not well-enough understood or because observations were not made in sufficient detail during relevant periods of time. However, we get very close to a mechanistic understanding for at least two groups of animals, the Lepidoptera (butterflies and moths) and birds. In both groups, extreme weather events appear to drive local population dynamics.

\section{Direct effects of extreme events}

Many population extinctions of Edith's Checkerspot butterfly (Euphydryas editha) have been associated with particular climatic events (Singer and Thomas 1996; Ehrlich et al. 1980; Singer and Ehrlich 1979). The 1975-77 severe drought over California caused the extinction of 5 out of 21 surveyed populations (Ehrlich et al. 1980; Singer and Ehrlich 1979). Extremely wet years caused opposite responses in two subspecies. Following winters with 50\%-150\% more precipitation than the average, E. Editha bayensis suffered population crashes in the vicinity of San Francisco Bay (Dobkin et al. 1987), while E. editha quino exhibited population booms in northern Baja, Mexico (Murphy and White 1984).

Twenty years of studies at one site in the Sierra Nevadas of California have implicated three extreme weather events in carving a pathway to extinction of a whole set of E. editha populations at $2400 \mathrm{~m}$ (Singer and Thomas 1996; Thomas et al. 1996). The first catastrophe occurred in 1989 when very low winter snowpack led to an early and unusually synchronous adult emergence in April (as compared to the usual June flight). So early, in fact, that flowers were not yet in bloom and most adults died from starvation. Just one year later another relatively light snowpack again caused adults to emerge early. Adult butterflies, adapted to summertime conditions of warmth and sun, suffered many deaths during a "normal" May snowstorm. Each of these events decreased the population size by an order of magnitude. The finale came but two years later in 1992 "when (unusually low) temperatures of $-5^{\circ} \mathrm{C}$ on June 16 , without insulating snowfall, killed an estimated $97 \%$ of the Collinisa (host) plants... . The butterflies had already finished flying and left behind young (caterpillars) that were not killed directly but starved in the absence of hosts" (Singer and Thomas 1996). As of the latest census (1999), these sites remained extinct.

The observed northward and upward range shift of E. editha during this century has occurred as a result of increased numbers of population extinctions at the southern range boundary and at lower elevations, with a symmetrical tendency toward population stability along the northern range boundary and at the highest elevations (Parmesan 1996). Thus, infrequent and severe climatic events, via short-term responses at the population level, appear to have driven a gradual range shift in this butterfly species.

In North American songbirds, the energy maintaining nighttime metabolic rates primarily comes from food acquired during the previous day. In winter, as ambient temperatures cool and nights lengthen, individuals in the north must maintain higher nighttime metabolic rates for a longer period than do conspecifics farther south. Therefore, on average, northern individuals use substantially more energy during the night than do individuals in the south. This process produces physiological limits that for the majority of wintering songbirds, defines their northern range boundaries. This limit is where the highest average sustainable nighttime metabolic rate for individuals is 2.5 times their basal rate (Root 1988b).

For example, if a northern cardinal (Cardinalis cardinalis) in Indiana had to sustain this rate all night, (perhaps due to a cold snap), individuals would have an estimated 12 hours of fat reserves remaining at dawn. Cardinals $800 \mathrm{~km}$ north in Michigan, which is near the northern range limit, would have only three hours (Root 1994). Simple extrapolation of these figures to the real world suggests that, when experiencing extreme weather (e.g., a severe snowstorm) that necessitates sustained nighttime metabolic rate above 2.5 times their basal, cardinals nearer the northern range limit are at greater risk of death than those farther south (Root 1994; Burger 1998).

Observed patterns of change in wild bird populations are consistent with such a process. For example, migratory birds have been reported to shift their abundances in relation to weather. During cold winters (e.g., increased days with the minimum temperature below a given threshold), abundances are higher in the southern portions of these species' ranges than in the north. The opposite is true when the weather is warmer (Root 1999). Such episodic local shifts in population abundances may ultimately result in species' range shifts, such as that suggested by the northward move- 
ment of many British birds over the last 20 years (Thomas and Lennon 1999).

What information do we have for other taxa? Freeze and precipitation tolerance is known for many plants. For example, trees only occur where annual precipitation is above $300 \mathrm{~mm}$. Further, tropical trees are killed by low temperatures ranging from $0^{\circ} \mathrm{C}$ to $10^{\circ} \mathrm{C}$, whereas temperate broadleaved deciduous trees can survive temperatures to $-40^{\circ} \mathrm{C}$, and many boreal species appear to be able to survive any extreme low (Woodward 1987). Mammals are also relatively well studied with respect to climatic limitations mediated by physiological processes. For instance, the ninebanded armadillo (Dasypus novemcinctus) requires $>38 \mathrm{~cm}$ annual precipitation and is further restricted to latitudes with fewer than 20-24 days below freezing throughout winter and to fewer than nine consecutive days below freezing (Taulman and Robbins 1996). Unfortunately, for most species these specific requirements are unknown, as derivations of suitable climatic envelopes are based largely on poor-resolution correlative data, and mean isoclines are commonly presented as sole predictors.

\section{Effects of extremes on morphology}

Energetic constraints not only limit distributions of species, but influence shape, size, and color of individuals as well (Hadly 1997). For example, in the Dulzura kangaroo rat (Dipodomys simulans), body size is related to climatic variability; individuals are smaller in habitats with pronounced seasonality (Sullivan and Best 1997). Butterflies absorb radiant heat faster if they are darker colored; and seasonal changes in melanism from spring to summer in the wings of the Pontia occidentalis butterfly appear to be driven by maximum temperature (Kingsolver 1995).

Moreover, impacts of extreme weather on one trophic level can cascade through a food web to affect other trophic levels. Darwin's seed-feeding finches in the Galapagos Islands provide a classic example of this. Variable precipitation affects absolute and relative seed production of different plants, causing dramatic changes in food availability and composition which in turn affect the finches' foraging success, competition, and breeding behavior. For one finch on Daphne Island, Geospiza fortis, wet years select for small individuals while droughts select for large ones, leading to frequent shifts in the distribution of body sizes (Boag and Grant 1984).

\section{Effects of extremes on behavior and reproduction}

Map turtles (Graptemys) provide a beautifully documented example of the consequences of exceeding temperature thresholds on a most basic trait—sexuality. In many reptiles, an individual's sex is determined by the maximum temperature experienced during a critical phase of embryonic development (reviewed by Bull 1980). In both laboratory and field manipulations on the map turtle, maximum incubation temperatures below $28^{\circ} \mathrm{C}$ produce only males, whereas maximum temperatures surpassing $30^{\circ} \mathrm{C}$ produce only females (Bull and Vogt 1979). Single-sex offspring are typical in a single nest, but an equilibrium population sex ratio is usually achieved by within-habitat microclimatic differences among nests and dispersal among populations.

Thus, changes in the incidence of extreme temperatures (high or low) through time could result in a highly skewed population sex ratio. Theoretically, a combination of dispersal and selection (e.g., on physiology or female nest choice) would correct this imbalance within an individual's lifetime (i.e., 30 years). However, the current trends in many wild turtles toward smaller population sizes, fewer and more isolated protected nesting habitats, (all leading to less successful dispersal), and limited choice of sites for nesting within a habitat, suggest that the assumption of selfadjustment of sex ratios may no longer be valid. Thus, impacts of shifting climatic distribution in the past cannot be simply extrapolated to the future.

Weather events may affect the timing of breeding by providing a cue. For example, the beginning of the rainy season may herald the onset of a temporal window in which to breed. It is thought that climatic variability itself promotes multifemale group breeding in the Galapagos mockingbird (Nesomimus parvulus): subordinate females will breed opportunistically in particularly wet years when food resources are high (Curry and Grant 1989). Less obvious, and perhaps less expected, is that weather extremes can also affect breeding in more complex ways. For instance, in African elephants (Loxodonta africana), breeding is year-round, but dominant males mate in the wet season and subordinate males breed in the dry season. Therefore, a change in the intensity or duration of the rainy versus drought seasons could change relative breeding rates and, hence, genetic structures in these populations (Poole 1989; Rubenstein 1992). 


\section{Effects on population and community dynamics}

Studies of effects of weather and climate on ecology and evolution at the population level are legion (Hoffmann and Parsons 1997; Saether 1997; Weiss et al. 1988; Precht et al. 1973; Wieser 1973; Singer 1972; Uvarov 1931). Although responses to extreme weather events vary, and may even be in opposite directions among different species in the same habitat, one important conclusion is that extreme weather can have major impacts on wild populations.

Consequences of drought are quite commonly studied. For example, a widespread drought in the 1987-88 caused simultaneous crashes of insect populations across the United States, affecting diverse taxa from butterflies to sawflies to grasshoppers (Hawkins and Holyoak 1998). Conversely, drought can be related to population booms in other insects (e.g., certain beetles, aphids, and moths) (Mattson and Haack 1987).

Heat and cold stresses are also implicated in population crashes, even in aquatic systems. For instance, heat stroke has been known to cause large losses of salmon in Canadian streams (Huntsman 1946). In a Michigan lake, $76 \%$ of fish species $(n=21)$ were severely affected by a single hot day in which water temperatures reached $38^{\circ} \mathrm{C}$ (Bailey 1955).

Moreover, these effects can go beyond natural systems to affect human welfare. A recent example of this comes from the southwestern desert of the United States where the 1991-92 El Niño caused unusually heavy precipitation in some areas (Glass et al. 2000). High precipitation promoted lush vegetative growth, which in turn was correlated with population booms of deer mice (Peromyscus maniculatus). This wild rodent carries the Hantavirus that is transmissible, and frequently lethal, to humans. Local overcrowding resulting from the wet-year population boom caused increased rodent activity in nearby human settlements. Subsequent increased human contact and transmission rates led to a major regional epidemic of the virus.

Fewer studies have documented community level changes due to extreme events, but these may also have large impacts. One example comes from the massive 1982-83 El Niño event that caused widespread loss (bleaching) of coral reef communities in the eastern and central Pacific (Coffroth et al. 1990). Similarly, hurricanes and typhoons have been documented to alter the composition of local communities (identity and abundance of species) ranging from snails (Willig et al. 1998) to bats (Willig and McGinley 1999; Gannon and Willig 1998).

\section{Effects at the ecosystem level}

Extreme, large-scale weather events are likely to trigger ecosystem-level disturbances. These disturbances may affect the organization (species composition and diversity) and functional attributes of entire ecosystems, from temperate grasslands to moist evergreen tropical forests (Walker 1999; Pickett and White 1985). Such disturbances result from hurricanes and typhoons, tornadoes, wildfires, floods, droughts, landslides, and even treefalls (Walker and Willig 1999; Willig and Walker 1999). The initial resistance, trajectory of response, and extent to which a system returns to original conditions (resilience) after a disturbance depends on the frequency, intensity, duration, and extent of disturbance, as well as the inherent properties of the biological system, including evolutionary history, and extent of invasion by exotic species (Willig and Walker 1999; Myers 1996; Zimmerman et al. 1996; Pickett and White 1985).

Biological responses to such disturbances are not necessarily related to responses to changes in mean climatic conditions. For instance, a typical response to increases in mean temperature would be for different tree species to (asynchronously) shift their distributions poleward and to higher elevations, ultimately affecting species composition, and hence forest structure. However, there are more indirect effects on forest composition that could act through changes in disturbance regime.

For instance, in the Sierra Nevadas of California, increased frequency of fires has been shown to be an important element in local forest dynamics (Swetnam 1993; Stephenson and Parsons 1993). Fire frequency is correlated to fuel loads (related to trees species composition and age structure), temperature, and fuel moisture. Periods of drought followed by weeks of extreme heat and low humidity provide ideal conditions for fire, which are, ironically, often sparked by lightning associated with thunderstorms at the drought's end. Recent modeling analyses (Miller and Urban 1999) suggest profound effects of small changes in temperature $\left(2^{\circ} \mathrm{C}\right)$ and precipitation $(20 \%)$ on forest structure and function. Depending on elevation, total woody biomass could decrease by more than an order of magnitude. Similarly, the species composition of montane forests could change by over $50 \%$. 
Clearly, alterations in local climates can have a dramatic effect on disturbance regimes and ecosystemlevel characteristics.

\section{Responses in light of limited options}

Studies of biological responses during the Pleistocene glaciation indicate that natural systems were fairly resilient to rapid climate change. Many species shifted their ranges across the globe, tracking the moving climate, while others were immobile and adapted to changing climate. Different lag times of response caused transient nonanalog communities to form, but these eventually reassembled into communities of similar taxonomic composition to those before the climatic transition (Davis and Zabinski 1992; Graham and Grimm 1990) with few global extinctions of species (Coope 1995; Cronin 1985; Potts and Garthwaite 1991; Paulay 1991).

Unfortunately, the modern human-dominated landscape has probably altered the potential of similar dynamics occurring with future climatic changes. Natural ecosystems increasingly are confined to smaller and more isolated fragments, and population sizes of wild nonweedy species have generally declined (Groombridge 1992). This has limited the options by which natural systems may contend with the predicted rapid changes in climatic extremes or in frequency and intensity of disturbances. Reduced population sizes often result in diminished genetic variation, which could limit potential for local adaptation. The increase in mean distance between natural habitats decreases successful dispersal, thereby hindering simple shifts of species' distributions. Increased fragmentation also lowers the probability of successful colonization of devastated areas after catastrophic disturbances because colonists not only have farther to travel, but are coming from smaller source populations within impoverished communities.

Consequently, modern systems have lowered resiliency to the types of nonlinear dynamic processes predicted by scenarios of global climate change (Schneider and Root 1996; see Easterling et al. 2000 and Meehl et al. 2000, this issue). Thus, to predict impacts of future changes in the shape and position of the climatic distribution, we need a much more precise understanding of the relationships between biotic processes and extreme weather events.

\section{Implications for future climatological research}

In general, biologists lack climatic analyses on ecologically relevant scales of time and space. Raw climatic data, which are increasingly available through Web sites, often have not been tested for inhomogeneity. As such, they may be risky for biologists to use blindly. Ideally, biologists could collaborate with climatologists to obtain climate analyses appropriate to the biological system in question, but such collaborations are limited in practice by the numbers of research pairs that can form. A more efficient alternative is to inform climatologists of the needs of biologists to ensure the development of databases that can be accessed easily and are directly applicable to biological research.

There are issues of resolution, scale, and analytical detail. From a quantitative standpoint, for any given climatic database, characterizations of variability as well as mean trends would be relatively simple to produce and yet enormously useful in application to biological studies (e.g., Mearns et al. 1984). Further, monthly and seasonal trends in temperature and precipitation become important to understanding biological patterns because many organisms are active during only a portion of the year. On an even finer level, absolute number of extreme days in a month or season are useful indices, as are the number of extreme days occurring in sequence.

Biological data are usually gathered at the level of a single site (field station) and more rarely within a single region (e.g., Sierra Nevadas, Mojave Desert, Great Plains). The resolution of a typical GCM $\left(5^{\circ} \times 5^{\circ} \mathrm{LL}\right)$ coupled with large-scaled analyses that look for mean trends over the entire globe, or perhaps a continent, are not particularly useful for correlations against these much more narrowly focused biological databases (Root and Schneider 1995).

\section{Conclusions}

Coupling of more detailed climatological analyses to biological processes will help identify the impacts of specific facets of a complex climatic regime on natural systems. As those mechanisms become better understood, mathematical models of the consequences of climate change will be free to extend beyond yearly and monthly means to a richer suite of biologically informed climatic variables. Specifically, changes in 
extreme weather events and in duration of time periods exceeding biological thresholds for temperature or precipitation are often neglected in doubled $\mathrm{CO}_{2}$ scenarios, but may be crucial components for predicting biological responses. More broadly, ecological and evolutionary theories, such as those concerning physiological energetics, population dynamics, and community structure, are likely to gain heuristic, descriptive, and predictive power from better spatial and temporal correspondence between climatic and biological analyses.

Acknowledgments. We thank the Aspen Global Change Institute and organizers of the workshop on climate extremes for stimulating discussions that led to this paper. Much of the writing took place at the National Center for Ecological Analysis and Synthesis. Advice on early drafts was provided by R. deGroot, S. L. Pimm, W. P. Porter, M. C. Singer, and F. Wagner.

\section{References}

Andrewartha, H. G., and L. C. Birch, 1954: The Distribution and Abundance of Animals. University of Chicago Press, 782 pp.

Bailey, R. M., 1955: Differential mortality from high temperature in a mixed population of fishes in southern Michigan. Ecology, 36, 526-528.

Barry, J. P., C. H. Baxter, R. D. Sagarin, and S. E. Gilman, 1995: Climate-related, long-term faunal changes in a California rocky intertidal community. Science, 267, 672-675.

Boag, P. T., and P. R. Grant, 1984: The classical case of character release: Darwins finches (Geospiza) on Isla Daphne Major, Galapagos. Biol. J. Linn. Soc., 22(3), 243-287.

Brown, J. H., G. C. Stevens, and D. M. Kaufman, 1996: The geographic range: Size, shape, boundaries and internal structure. Annu. Rev. Ecol. Syst., 27, 597-623.

Bull, J. J., 1980: Sex determination in reptiles. Quart. Rev. Biol., 55, 3-21.

— mination in turtles. Science, 206, 1186-1188.

Burger, M., 1998: Physiological mechanisms limiting the northern boundary of the winter range of the Northern Cardinal (Cardinalis cardinalis). Ph.D. dissertation, University of Michigan.

Carter, R. N. and S. D. Prince, 1988: Distribution limits from a demographic viewpoint. Plant Population Ecology, A. J. Davy et al., Eds., Blackwell Scientific Publications, 165-184.

Coffroth, M. A., H. R. Lasker, and J. K. Oliver, 1990: Coral mortality outside of the eastern pacific during 1982-1983: Relationship to El Niño. Global Ecological Consequences of the 1982-1983 El Niño-Southern Oscillation, P. W. Glynn, Ed., Elsevier.

Coope, G. R., 1995: Insect faunas in ice age environments: Why so little extinction? Extinction Rates, J. H. Lawton and R. M. May, Eds., Oxford University Press, 55-74.

Cronin, T. M., 1985: Speciation and stasis in marine ostracoda: Climatic modulation of evolution. Science, 227, 60-63.
Curry, R. L., and P. R. Grant, 1989: Demography of the cooperatively breeding Galapagos mockingbird, Nesominus parvulus, in a climatically variable environment. J. Anim. Ecol., 58 (2), 441-464.

Davis, M. B., and C. Zabinski, 1992: Changes in geographical range resulting from greenhouse warming: Effects on biodiversity in forests. Gloal Warming and Biological Diversity, R. L. Peters and T. E. Lovejoy, Eds., Yale University Press, 297-308.

Dobkin, D. S., I. Olivieri, and P. R. Ehrlich, 1987: Rainfall and the interaction of microclimate with larval resources in the population dynamics of checkerspot butterflies (Euphydryas editha) inhabiting serpentine grassland. Oecologia, 71, 161-166.

Easterling, D. R., J. L. Evans, P. Ya. Groisman, T. R. Karl, K. E. Kunkel, and P. Ambenje, 2000: Observed variability and trends in extreme climate events: A brief review. Bull. Amer. Meteor. Soc., 81, 417-425.

Ehrlich, P. R., D. D. Murphy, M. C. Singer, C. B. Sherwood, R. R. White, and I. L. Brown, 1980: Extinction, reduction, stability and increase: The responses of checkerspot butterfly (Euphydryas editha) populations to the California drought. Oecologia, 46, 101-105.

Gannon, M. R., and M. R. Willig, 1998: Long-term monitoring protocol for bats: lessons from the Luquillo Experimental Forest of Puerto Rico. Forest Biodiversity in North, Central, and South America and the Caribbean: Research and Monitoring, F. Dallmeier and J. Comisky, Eds, Man and the Biosphere Series, Vol. 21, UNESCO and Parthenon Press, 271-291.

Glass, G. E., and Coauthors, 2000: Anticipating risk areas for hantavirus pulmonary syndrome with remotely sensed data: Re-examination of the 1993 outbreak. Emerg. Infect. Dis., in press.

Grabherr, G., M. Gottfried, and H. Pauli, 1994: Climate effects on mountain plants. Nature, 369, 448.

Grace, J., 1987: Climatic tolerance and the distribution of plants. New Phytol. (Suppl.), 106, 113-130.

Graham, R. W., 1986: Responses of mammalian communities to environmental changes during the late Quaternary. Community Ecology, J. Diamond, and T. J. Case, Eds., Harper and Row, 300-313.

— on the patterns of terrestrial biological communities. Trends Ecol. Evol., 5, 289-292.

Groombridge, B., Ed., 1992: Global Biodiversity: Status of the Earth's Living Resources, Chapman and Hall, 585 pp.

Hadly, E. A., 1997: Evolutionary response of pocket gopher (Thomomys talpoides) to late-Holocene climatic change. Biol. J. Linn. Soc., 60, 277-296.

Hawkins, B. A., and M. Holyoak, 1998: Transcontinental crashes of insect populations? Amer. Nat., 152, 480-484.

Hersteinsson, P., and D. W. Macdonald, 1992: Interspecific competition and the geographical distribution of red and arctic foxes Vulpes vulpes and Alopex lagopus. Oikos, 64, 505-515.

Hoffman, A. A., and P. A. Parsons, 1997: Extreme Environmental Change and Evolution. Cambridge University Press.

Huntsman, A. G., 1946: Heat stroke in Canadian maritime stream fishes. J. Fish Res. Board Can., 6, 476-482.

Kingsolver, J. G., 1995: Viability selection on seasonally polyphenic traits: wing melanin pattern in western white butterflies. Evolution, 49, 932-941. 
MacArthur, R. M., 1972: Geographical Ecology. Harper and Row, $269 \mathrm{pp}$.

Mattson, W. J., and R. A. Haack, 1987: The role of drought in outbreaks of plant-eating insects. Bioscience, 37, 110-118.

Mearns, L. O., R. W. Katz, and S. H. Schneider, 1984: Changes in the probabilities of extreme high temperature events with changes in global mean temperature. J. Climate Appl. Meteor., 23, 1601-1612.

Meehl, G. A., F. Zwiers, J. Evans, T. Knutson, L. Mearns, and P. Whetton, 2000: Trends in extreme weather and climate events: issues related to modeling extremes in projections of future climate change. Bull. Amer. Meteor. Soc., 81, 427436.

Miller, C., and D. L. Urban, 1999: A model of surface fire, climate and forest pattern in Sierra Nevada, California. Ecol. Modell., 114, 113-135.

Murphy, D. D., and R. R. White, 1984: Rainfall, resources, and dispersal in southern populations of Euphydryas editha (Lepidoptera: Nymphalidae). Pan-Pacific Entom., 60, 350-354.

Myers, N., 1996: Two key challenges for biodiversity: Discontinuities and synergisms. Biodiver. Conserv., 5, 1024-1034.

Parmesan, C., 1996: Climate and species' range. Nature, 382, $765-766$.

__ , and Coauthors, 1999: Poleward shifts in geographical ranges of butterfly species associated with regional warming. Nature, 399, 579-583.

Paulay, G., 1991: Late cenozoic sea level fluctuation and the diversity and species composition of insular shallow water marine faunas. The Unity of Evolutionary Biology, E. C. Dudley, Ed., Dioscorides Press, 184-193.

Pickett, S. T. A., and P. S. White, Eds., 1985: The Ecology of Natural Disturbance and Patch Dynamics. Academic Press, $472 \mathrm{pp}$.

Poole, J. H., 1989: Announcing intent: The aggressive state of musth in African elephants. Anim. Behav., 37, 140-152.

Potts, D. C., and R. L. Garthwaite, 1991: Evolution of reef-building corals during periods of rapid global change. The Unity of Evolutionary Biology, E. C. Dudley, Ed., Dioscorides Press, 170-178.

Pounds, J. A., M. P. L. Fogden, and J. H. Campbell, 1999: Biological response to climate change on a tropical mountain. Nature, 398, 611-615.

Precht, H., J. Christophersen, H. Hensel, and W. Larcher, 1973: Temperature and Life, Springer-Verlag, 779 pp.

Root, T. L., 1988a: Environmental factors associated with avian distributional limits. J. Biogeogr., 15, 489-505.

- 1988b: Energy constraints on avian distributions and abundances. Ecology, 69, 330-339.

__ 1994: Scientific/philosophical challenges of global change research: A case study of climatic changes on birds. Proc. Amer. Philos. Soc., 138, 377-384.

_ 1999: Chapter 21. Earth Systems: Processes and Issues, G. Ernst, Ed., Cambridge University Press.

— strategies and implications. Science, 269, 334-341.

Rubenstein, D. I., 1992: The greenhouse effect and changes in animal behavior: Effects on social structure and life-history strategies. Global Warming and Biological Diversity, R. L. Peters and T. E. Lovejoy, Eds., Yale University Press, 180192.
Saether, B.-E., 1997: Environmental stochasticity and population dynamics of large herbivores: A search for mechanisms. Trends Ecol. Evol., 12, 143-149.

Sagarin, R. D., J. P. Barry, S. E. Gilman, and C. H. Baxter, 1999: Climate-related change in an intertidal community over short and long time scales. Ecol. Monogr., 69, 465-490.

Schneider, S. H., and T. L. Root, 1996: Ecological implications of climate change will include surprises. Biodiver. Conserv., 5, 1109-1119.

Singer, M. C., 1972: Complex components of habitat suitability within a butterfly colony. Science, 176, 75-77.

- , and P. R. Ehrlich, 1979: Population dynamics of the checkerspot butterfly Euphydryas editha. Fortschr. Zool., 25, 53-60.

— , and C. D. Thomas, 1996: Evolutionary responses of a butterfly metapopulation to human and climate-caused environmental variation. Amer. Nat., 148, S9-S39.

Stephenson, N. L., and D. J. Parsons, 1993: A research program for predicting the effects of climate change on the Sierra Nevada. Proceeding of the Fourth Conference on Research in California's National Parks, S. D. Veirs et al., Eds., Transactions and Proceedings Series, Vol. 9, U.S. Department of Interior, National Park Service, 93-109.

Sullivan, R. M., and R. L. Best, 1997: Effects of environment on phenotypic variation and sexual dimorphism in Dipodomys simiulans (Rodentia: heteromyidae). J. Mammal., 78, 798-810.

Swetnam, T. W., 1993: Fire history and climate change in giant sequoia groves. Science, 262, 885-889.

Taulman, J. F., and L. W. Robbins, 1996: Recent range expansion and distributional limits of the nine-banded armadillo (Dasypus novemcinctus) in the United States. J. Biogeogr., 23, 635-648.

Thomas, C. D., and J. J. Lennon, 1999: Birds extend their ranges northwards. Nature, 399, 213.

— M. C. Singer, and D. A. Boughton, 1996: Catastrophic extinction of population sources in a butterfly metapopulation. Amer. Nat., 148, 957-975.

Uvarov, B. P., 1931: Insects and climate. Roy. Entomol. Soc. London, 79, 174-186.

Walker, L. R., Ed., 1999: Ecology of Disturbed Ground. Elsevier Science, 868 pp.

— turbance. Ecology of Disturbed Ground, Elsevier Science, 116.

Wieser, W., Ed., 1973: Effects of Temperature on Ectothermic Organisms. Springer-Verlag, 298 pp.

Weiss, S. B., D. D. Murphy, and R. R. White, 1988: Sun, slope, and butterflies: Topographic determinants of habitat quality for Euphydras editha. Ecology, 69, 1486-1496.

Willig, M. R., and L. R. Walker, 1999: Disturbance in terrestrial ecosystems: Salient themes, synthesis, and future directions. Ecology of Disturbed Ground, Elsevier Science, 747-767.

- , and M. A. McGinley, 1999: Animal responses to natural disturbance and roles as patch generating phenomena. Ecology of Disturbed Ground, Elsevier Science, 667-689.

—, M. F. Secrest, S. B. Cox, G. R. Camilo, R. J. Cary, J. Alvarez, and M. R. Gannon, 1998: Long-term monitoring of snails in the Liquillo Experimental Forest of Puerto Rico: Heterogeneity, scale, disturbance, and recovery. Forest Biodiversity in North, Central, and South America and the Caribbean: 
Research and Monitoring, F. Dallmeier and J. Comisky, Eds., Man and the Biosphere Series, Vol. 21, UNESCO and Parthenon Press, 293-322.

Woodward, F. I., 1987: Climate and Plant Distribution. Cambridge University Press, 174 pp.
Zimmerman, J. K., M. R. Willig, L. R. Walker, and W. L. Silver, 1996: Introduction: Disturbance and Caribbean ecosystems. Biotropica, 28, 756-765.

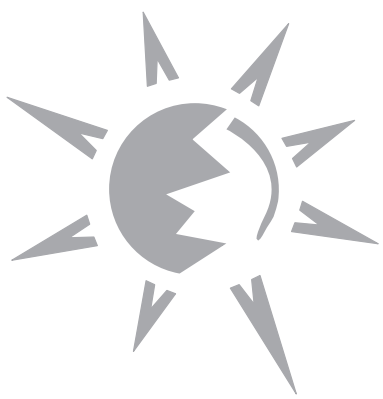

